\title{
Cost Analysis of Eye Surgeries and Comparison with Approved Governmental Tariffs
}

\author{
Ali Janati, ${ }^{1}$ Mohammad Farough Khosravi, ${ }^{2,}{ }^{*}$ Ali Imani, ${ }^{1}$ Alireza Javadzadeh, ${ }^{3}$ and Mohammadali \\ Mazhar Gharamaleki ${ }^{4}$ \\ ${ }^{1}$ Department of Health Services Management, School of Management and Medical Informatics, Iranian Center of Excellence in Health Management, Tabriz University of \\ Medical Sciences, Tabriz, Iran \\ ${ }^{2}$ Department of Health Services Management, School of Management and Medical Informatics, Tabriz University of Medical Sciences, Tabriz, Iran \\ ${ }^{3}$ Department of Ophthalmology, Tabriz University of Medical Sciences, Tabriz, Iran \\ ${ }^{4}$ Nikookari Ophthalmic Teaching Hospital, Tabriz University of Medical Sciences, Tabriz, Iran \\ "Corresponding author: Mohammad Farough Khosravi, Department of Health Services Management, School of Management and Medical Informatics, Tabriz University of \\ Medical Sciences, Tabriz, Iran. Tel/Fax: +98-4133358291, E-mail: khosravi.mohammad1@yahoo.com
}

Received 2016 June 11; Revised 2016 September 20; Accepted 2016 October 02.

\begin{abstract}
Background: Cost and cost analysis is a managerial tool that can place needed data at managers' disposal and help them in making informed decisions in investing services and infrastructures.

Objectives: The aim of this study was to estimate the cost of eye surgeries and compare them with tariffs approved by the Iranian ministry of health.

Methods: The present retrospective-descriptive study was carried out at Nikookari ophthalmic hospital, from April 2013 to April 2014, in Tabriz, Iran. Surgical operations of cataract, strabismus and glaucoma were considered on the grounds that they were global and the most frequent. The required data was collected through conducting interviews with experts and relevant units, direct observation of activities, analysis of documents in the financial department, and hospital information system (HIS) and financial software system of the hospital. The cost of surgical operations was estimated by activity based costing (ABC).

Results: According to the findings, the amount and the share of the total costs of the activities identified in the main centers were as following: human resources \$2 818 722, depreciation of medical equipment \$277 233, consumable medicals and supplies \$218,484, building depreciation $\$ 138004$, depreciation of non-medical equipment $\$ 43640$, consumable non-medicals and supplies \$26804, utility costs $\$ 4724$, and costs of indirect units $\$ 864455$. Ultimately, the costs of different surgeries were estimated to be as follows: strabismus surgery $\$ 464$, glaucoma $\$ 505$ and cataract surgery $\$ 400$, which respectively had $\$ 235, \$ 298$ and $\$ 75$ difference with the approved governmental tariffs.

Conclusions: This price gap can negatively affect the performance and quality of services provided by hospitals in the long term. Since the costs of personnel, indirect costs and depreciation of medical equipment account for $90 \%$ of the total costs of surgery, hospital managers should pay more attention to these issues in order to improve efficiency and reduce costs.
\end{abstract}

Keywords: Activity-Based Costing, Eye Surgery, Tabriz, Costs and Costs Analysis, ABC

\section{Background}

Currently, the health system is faced with many problems and challenges in striking a balance between resources restrictions and providing desired services (1). Technological advancement, population growth and increase in public expectations have imposed increasing cost upon the health section and forced managers not only to provide quality services with the least cost but also to expand their services (2).

One of the most important factors in regulating the relationship between clients and providers in health service market are tariffs and their payment method (3). Tariffing is one of the most important tools of policy makers of health systems in any country, and effects equality, ef- fectiveness, quality and responsibility of the provided services (4). If tariffs are not determined in an accurate and principled way, they will have an adverse effect on treatment services (5). The process of tariffing health services in Iran showed that new tariffs have been announced for the coming years with an increase, and negotiation has had a significant role in determining the tariffs (6).

The important challenge in health service tariffing is lack of necessary and sufficient theoretical as well as practical knowledge in the field (6). Some believe that tariffs are not realistic (7). The results of the study done by Noori et al. (8) showed that the basis of medical tariffing in our country (Iran) does not follow scientific principles and during the recent years it has failed to cover the costs of services. Hospitals claim that tariffs of services are not 
realistic and fair (9). Moreover, they believe that the costs of services provided for patients are more than approved tariffs, so hospitals experience a lot of losses (10). For instance, findings from studies conducted by Nouroozi and Salehi (11), Rajabi and Dabiri (12), Moreno (13) and Rajabi (14) confirmed this claim and showed that there is a significant difference between the costs of services provided and the approved tariffs, which has caused studied sections to sustain considerable losses.

As no country has sufficient resources to meet all the needs of their population, hospital managers need exact and accurate data in order to improve their effectiveness and performances (15). One of the most important pieces of information needed by hospital managers is costing information, which allows them to make right decisions and to price accurately (16). In fact, they cannot make their decisions without accurate and reliable data (16). With economic development and increasing competition, a search for new methods of costing which are compatible with increasing health demands and competition is necessary (14).

Nowadays, many companies have found that activity based costing $(\mathrm{ABC})$ is one of the best methods of costing (17). This method, as a tool of effectiveness and cost control, was developed between 1970 and 1980, and allows organizations to benefit from their resources while providing products and services to their customers, and calculates costs of different activities (18). However, this method can be expensive to both implement and maintain in terms of time and money (19). The main motivation for using this method can be attributed to accurate estimation of costs and full unit costs (1). Additionally, applying this method in health sectors supports its suitability for developing countries (17).

Duffy et al. (20) suggested that in comparison with the tariff method, the $A B C$ method data is very suitable and applicable for decision-making. van Rensburg et al. (15) showed that the ABC method not only can facilitate management of cost centers, it can also decrease and optimize costs. Furthermore, Tibesku et al. (21) concluded that using the $\mathrm{ABC}$ method in calculating hospital costs could increase efficiency in hospital services. Similarly, this method can be effective in reforming tariff rate.

It seems that if tariffs of services are proportionate with their real costs, hospitals and remedial centers will not face any problems in funding, while observing the approved tariffs (6).

Although, nowadays, diseases as such cancer, Alzheimer's, diabetes, and cardiovascular diseases are among serious complications, which are found in a large number of patients. In addition, eye diseases are among important diseases, which also involves a large group of patients. If they are not treated in time, patients will go blind bringing about irreparable problems (22).

\section{Objectives}

Due to considerable features of $\mathrm{ABC}$ and its suitability for developing countries, the aim of this study was to estimate the costs of eye surgeries and to compare these estimations with tariffs approved by the Iranian ministry of health.

\section{Methods}

Nikookari medical training center is a state owned specialized ophthalmic hospital, which currently has 82 beds (60 approved beds) with 50\% occupancy rate.

\subsection{Strabismus Costing Method}

This was a retrospective-descriptive study, which was carried out from April 2013 to April 2014, in Tabriz, Iran. As surgical operations of cataract, strabismus and glaucoma are global and the most frequent, they were included in the study, excluding other less frequent surgical operations. An unstructured interview was conducted to identify the admission process and how the surgeries were performed. The required data were collected through literature and documents review that were present at the financial department. Furthermore, the hospital information system (HIS) and other financial software systems of the hospital were used for data gathering purposes. Data were collected after obtaining permission from the hospital management. The costs of surgical operations were estimated using ABC of Excel 2013.

Steps of costing in the present study were as follow:

\subsection{Identification of All Activities and Separation of Units}

During this step, by studying the documents and instructions on how to provide services and interviewing relevant experts, various types of services together with their sequence from admission to discharge were determined.

\subsection{Costing in Activity Centers}

The costs identified in this study were as following:

\subsubsection{Human Resources Cost}

First, information on the staff working at each unit was gathered. Then, the costs of permanent employees as well as the costs of employees hired on a contractual basis working at each unit were extracted from the payroll system and the financial software. Finally, pension, premium, overtime payment and remuneration were added to obtain the total human resources cost. 


\subsubsection{Utilities Cost}

Based on references, this cost driver was used since the information about the equipment was unavailable. The total cost of utility services, which includes water, electricity, gas, and telephone, was estimated by referring to the accounting unit. Costs of water, electricity and gas were determined on the basis of the area and telephone and Internet costs were divided by the number of lines available.

\subsubsection{Consumable Medications and Supplies, Consumable Non- Medications and Supplies}

By referring to the warehouse a list of all items delivered to various hospitals centers was prepared.

\subsubsection{Medical and Non-Medical Equipment Depreciation Cost}

A list of equipment available for each activity center with detailed information on their purchase time, price, and maintenance were prepared. To determine the depreciation of equipment, sum of the Years' Digits was applied (As the purchase price of the equipment was not available, after applying inflation rate, the price was updated and used).

SYD $=n(n+1) / 2, n=$ estimated useful life, Depreciation Expense $=($ Un-depreciated useful life $/$ SYD $) \times$ Depreciable Amount

\subsubsection{Building Depreciation}

First, according to the hospitals' map and with the help of technical experts, the area of each activity center was determined. Since the technical management experts of Tabriz University of Medical Sciences declared that the useful life of the building had ended, approximate monthly rental cost of the hospital was estimated. Then, the cost of each hospital ward was determined based on its area. Appropriate cost drivers for each of the main and overhead activity centers were identified.

\subsection{Identification of Appropriate Cost Driver}

At this step, appropriate cost drivers were identified for each activity center (Tables 1 and 2 ).

\subsection{Allocation of Costs to Activity Centers}

Cost Allocation was done in two steps. First, the cost of each overhead activity center was allocated to strabismus surgery centers. Then, the cost of main strabismus surgery centers was allocated to activities and services.

\subsection{Calculation of the Cost of Strabismus Surgery}

The total cost of a surgical operation includes the sum of patient's admission cost, prognostic activities, preoperative cares and postoperative cares, surgery and discharge costs.

\section{Results}

In the first step, by reviewing the documents and instructions on how to provide services, face to face interviews with relevant experts, various types of services provided and their sequence from admission to discharge were determined (Figure 1).

Hospital units were divided to two units: main surgical units and support units. In the third and fourth steps, the costs of these units and appropriate cost drivers were determined (Tables 1 and 2). In order to allocate costs, in the first step, the cost of support activity centers was allocated to the patient's main surgical units. Then, after dividing overhead (support units) costs to main surgical units, the total cost of patient's main surgical units was obtained (Table 3).

In the second step of allocation, the cost of main surgical activity centers was allocated to the performed activities using appropriate cost drivers (Tables 1 ).

Calculation of the costs of these centers and their allocation to patients were done as follows:

\subsection{Admission}

Annual cost per patient admission was $\$ 285699$ that is $85 \%$ for inpatient admission and $15 \%$ for outpatient admission $(23,24)$. Therefore, the total cost for the admission of inpatients was estimated to be $\$ 242844$. The number of patients admitted to the studied hospital was 11243. As a result, the cost for hospitalization of each patient was obtained as $\$ 22$.

\subsection{Diagnostic Activities Cost}

\subsubsection{Laboratory Cost}

Laboratory cost was $\$ 98656$ per year. Since the same tests were performed for all patients at this hospital, laboratory cost was assumed to be the same for all patients. In total, 13824 patients had referred to the laboratory and the cost for each was calculated as \$7.

\subsubsection{Electrocardiography Service Cost}

The total cost of electrocardiography unit per year was estimated as $\$ 17175$. In 2013, 6130 cases of electrocardiography were recorded and the cost for each patient was obtained as $\$ 3$.

\subsection{Preoperative and Postoperative Care}

The costs related to preoperative and postoperative care were estimated as $\$ 940660$. Allocation of the costs related to this part was based on the number of occupied days for a bed. Occupied bed days in the studied hospital was 16036 and the cost for each day of hospitalization was 


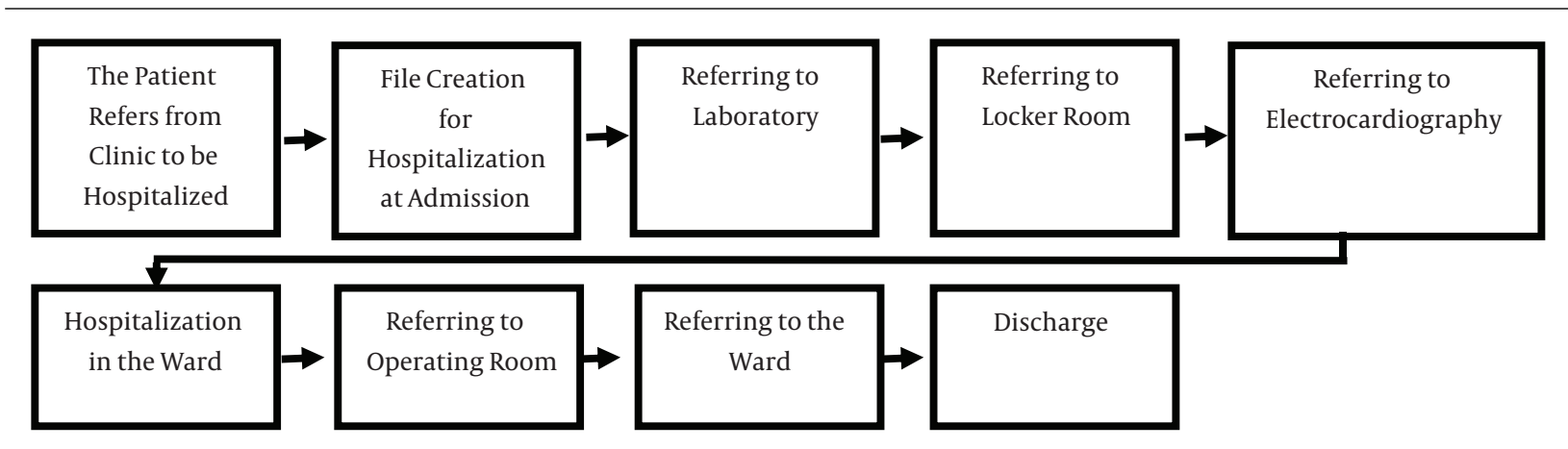

Figure 1. The Process of Admission to Discharge at Nikookari Ophthalmic Hospital

Table 1. Main Center of Surgery Cost Drivers

\begin{tabular}{|c|c|c|}
\hline Cost Center & Cost Driver & Cost \\
\hline Patient admission & $85 \%$ inpatient; $15 \%$ outpatient & 171,559 \\
\hline \multicolumn{3}{|l|}{ Diagnostic activities } \\
\hline Laboratory & Number of patients & 70,123 \\
\hline Electrocardiography & The number of $x$-rays taken for each patient & 11,499 \\
\hline Preoperational procedures (in ward) and patient care & Days of care & 436,018 \\
\hline Surgeries & The relative value unit of surgeries & $2,802,679$ \\
\hline Patient discharged & The number of patients discharged & 35,731 \\
\hline
\end{tabular}

Table 2. Supporting Center of Strabismus Surgery Cost Drivers

\begin{tabular}{|c|c|c|}
\hline Supporting Units & Cost Drivers & $\operatorname{Costs}(\$)$ \\
\hline $\begin{array}{l}\text { Presidency and management, accounting, administrative services, telephone center, } \\
\text { security }\end{array}$ & The number personnel & 312597 \\
\hline Kitchen & The number of staff and patient & 82929 \\
\hline Warehouse equipment, facilities and food & The number of delivered items in terms of activity center & 17480 \\
\hline Pharmacies and drug warehouse & The number of delivered items & 39584 \\
\hline Security station, information and facilities & The physical size of each unit & 164012 \\
\hline Laundry & The number of staff, days of care & 14025 \\
\hline Informatics & The number of computers in each department & 11119 \\
\hline Medical equipment & The number of existing equipment in departments & 12111 \\
\hline Nursing office & Number of employees covered by the nursing office & 35870 \\
\hline
\end{tabular}

estimated as $\$ 59$. Considering that stay duration of strabismus and glaucoma surgery was two days, the cost per patient was \$117. Similarly, stay duration for cataract was 2.3 days. In fact, the cost per patient was calculated as $\$ 135$.

\subsection{Surgery Cost}

These costs include the cost of the recovery room, sterilization and operating room. To estimate the cost of stra- bismus surgery in the operation room, the following formula was used:

Total cost of operation room $\times$ (number of strabismus surgeries $\times$ relative value of strabismus surgery) / sum of (relative value of each surgery conducted in the operation room $\times$ number of that surgery).

The total cost of a strabismus surgery was $\$ 162777$. The total number of strabismus surgeries conduced in the 


\begin{tabular}{|c|c|c|c|c|c|c|c|c|c|c|c|}
\hline \multirow[t]{2}{*}{ Row } & & \multirow[t]{2}{*}{ Activity Center } & \multirow{2}{*}{$\begin{array}{l}\text { Cost of Human } \\
\text { Resources }\end{array}$} & \multicolumn{3}{|c|}{ Depreciation } & \multirow{2}{*}{$\begin{array}{c}\text { Non-Medical } \\
\text { Consumable } \\
\text { Materials }\end{array}$} & \multirow{2}{*}{$\begin{array}{c}\text { Medical } \\
\text { Consumable } \\
\text { Materials }\end{array}$} & \multirow{2}{*}{$\begin{array}{c}\text { Utility } \\
\text { Facilities }\end{array}$} & \multirow[t]{2}{*}{ Indirect Costs } & \multirow[t]{2}{*}{ Total } \\
\hline & & & & $\begin{array}{c}\text { Depreciation } \\
\text { of Building }\end{array}$ & $\begin{array}{c}\text { Depreciation } \\
\text { of Medical } \\
\text { Equipment }\end{array}$ & $\begin{array}{l}\text { Depreciation } \\
\text { of Non-Medical } \\
\text { Equipment }\end{array}$ & & & & & \\
\hline 1 & & Admission & 134116 & 26162 & 0 & 2,052 & 7472 & 0 & 1,757 & 114140 & 285699 \\
\hline \multirow[t]{2}{*}{2} & & Laboratory & 51579 & 9811 & 2,609 & 1,734 & 965 & 3188 & 237 & 28533 & 98656 \\
\hline & $\begin{array}{l}\text { Diag- } \\
\text { nostic } \\
\text { activi- } \\
\text { ties }\end{array}$ & Electrocardiography & 9442 & 981 & 195 & 457 & 51 & 350 & 24 & 5,676 & 17175 \\
\hline 3 & & $\begin{array}{l}\text { Preoperative } \\
\text { and } \\
\text { postoperative } \\
\text { care }\end{array}$ & 307920 & 71945 & 7821 & 16836 & 9,362 & 20218 & 1,915 & 504642 & 940660 \\
\hline 4 & & surgery & 2283947 & 26162 & 266608 & 21846 & 8667 & 194728 & 720 & 187558 & 2990237 \\
\hline 5 & & Discharge & 31718 & 2,943 & 0 & 714 & 285 & 0 & 71 & 23905 & 59636 \\
\hline
\end{tabular}

studied hospital was 529. Thus, the cost of each strabismus surgery was found to be $\$ 308$.

The total cost of glaucoma was $\$ 79860$. The total number of glaucoma surgeries conduced was 229. In fact, the cost of each glaucoma surgery was $\$ 349$.

Likewise, the total cost of cataract was $\$ 1075795$. The total number of cataract surgeries operated was 4782. In another words, the cost of each cataract surgery was \$225.

\subsection{Patient Discharge Cost}

A total of 8046 patients had been discharged from the studied hospital in 2013 and the discharge cost of each patient was $\$ 7$.

Finally, The cost of each strabismus, glaucoma and cataract surgery were calculated to be $\$ 464, \$ 505$ and $\$ 400$, respectively, which deviate $\$ 235$, \$289 and \$75 from the approved tariffs in the order already mentioned (Global Surgery Tariff (in 2013-2014) of Strabismus surgery (one or both eyes), glaucoma and Cataract were \$229, \$207 and \$325\$).

The share of costs related to the main and secondary activity centers is shown in Figure 2.

\section{Discussion}

The present study aimed to estimate the cost of eye surgeries in Nikookari ophthalmic hospital of Tabriz, comparing it with the tariffs approved by the Iranian ministry of health. Results showed the total cost of strabismus, glaucoma and cataract surgeries in the studied hospital were \$464, \$508 and \$340, respectively.

According to the findings of the present study, personnel cost had the highest share of allocated costs. In the studies conducted by Noroozi and Salehi (11) and Rajabi and Dabiri (12), human resources cost was reported as
$60.93 \%$ and $49.3 \%$ of the total costs. In a study carried out at Kashani hospital, Iran, (2) human resources cost was more than $59 \%$, which accounted for the highest share of total costs. These findings confirm the results obtained in the present study. Although the share of human resources cost to total costs varied in these studies, personnel cost in all of them accounted for the highest share of the total costs. Since human resources cost is the main cost in the production and provision of services, improved performance in the field of human resources, can play the most significant role in reducing the unit costs of services.

The second part of major costs belonged to indirect costs. Analyzing the components of these costs can greatly help the hospital manager in providing required information for budgeting activity center and the entire hospital system. A study done in Ireland showed that more than $50 \%$ of the total costs was indirect cost (25). In addition, another study conducted in a Canadian hospital, (26) and Qaem hospital, in Firooz Abad, Iran (27), revealed that indirect costs roughly comprised up to $45 \%$ and $28.7 \%$ of the total cost of the hospitals, respectively. In our research, these costs made up a lesser amount. High indirect costs mean that activity centers' potentials are not used properly. If the volume of service provided increases, the total cost of services offered in every unit decreases.

Medical equipment depreciation cost ranks third after personnel costs and indirect costs. In the studies conducted by Noroozi et al. (27), Rajab and Dabiri (12) and Noroozi and Salehi (11), the cost of depreciation of medical equipment was estimated to reach $17 \%, 12.7 \%$ and $5.29 \%$, respectively. This can be due to excessive obsolescence of equipment, installation of new equipment (the highest depreciation of equipment occurs in the first years and the last years of their useful life), and existence of specialized equipment in this hospital and high cost of their main- 


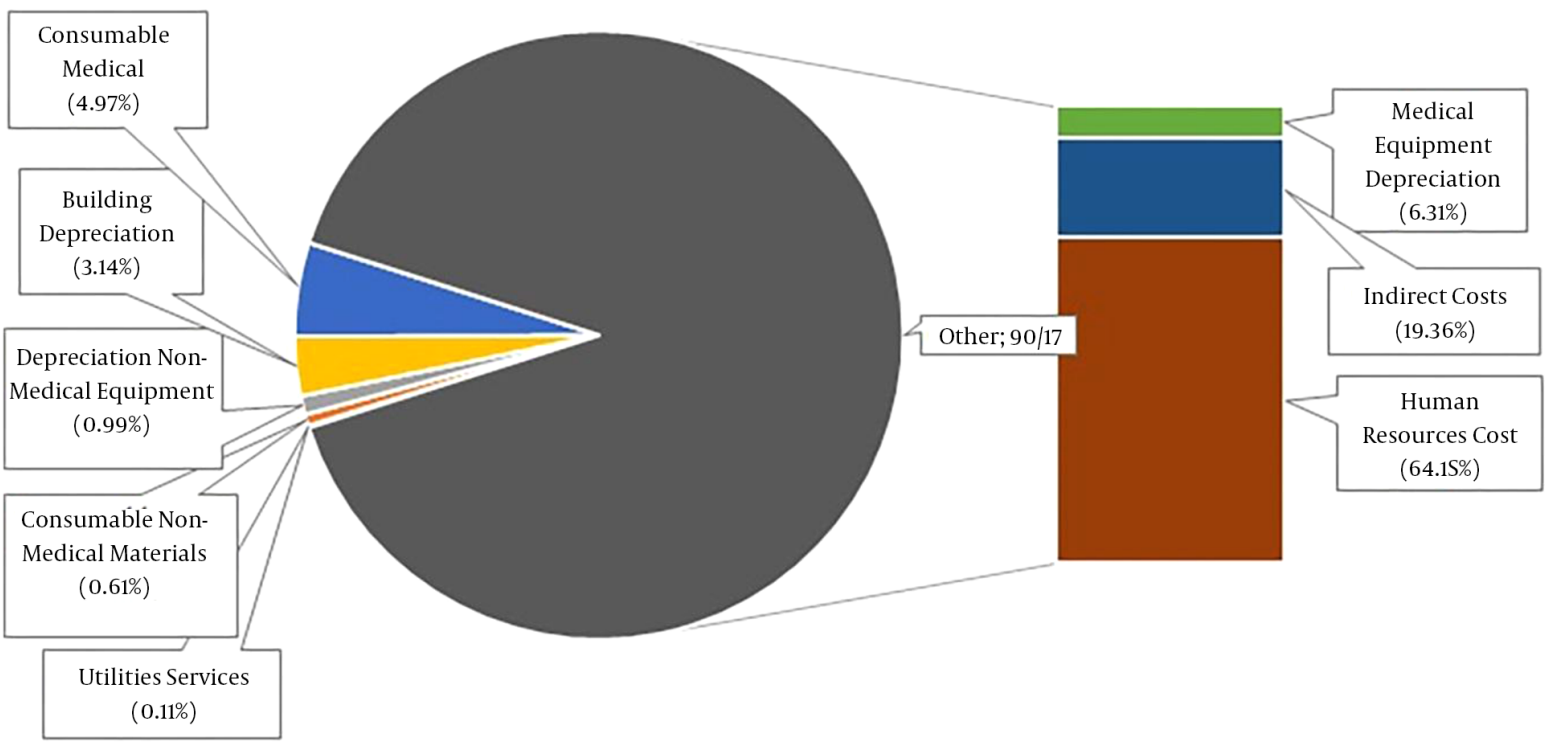

Figure 2. The Share of Costs at the Main Surgery Unit of Nikookari Ophthalmic Hospital of Tabriz

tenance. Among factors, which can affect depreciation of medical equipment, are unnecessary facilities, improper and misuse of equipment, and use of equipment in an inappropriate area. Other factors, which can help increase the cost, may be excessive depreciation of equipment and installing new equipment (equipment have the most depreciation rate during some first and last years of their useful life). Furthermore, costs may be higher if a hospital is specialized and has specialized equipment, which require higher maintenance cost.

Other share of costs belonged to medical supplies and medicine, building depreciation, depreciation of nonmedical equipment, consumable non-medical and utilities cost, respectively. Lower ratio of utilities' cost compared with other costs of hospitals may be due to the governmental subsidies paid to this sector. Since the studied hospital was a training one, for which teaching tariff should be estimated, utilities cost should also be studied without considering the subsidies.

According to the results of the present study, the costs of the selected surgeries were higher than the tariff approved by the Ministry of Health. In fact, there was a considerable difference between them, causing the hospital to suffer from a loss of \$551.207 in the year when the study was undertaken. Obviously, this gap can decrease the efficiency as well as the effectiveness of the hospital. Lower tariffs result in deficit, which, in turn, leads to a decrease in efficiency but increases the pressure on the vulnerable stratum of the community.
The results of previous studies $(24,28)$ showed that the cost of services widely differ from the costs calculated through the ABC method. Antikainen et al. (29) showed that the costs estimated based on $\mathrm{ABC}$ are more than the approved tariff, which was attributed to lack of consideration of the cost of unused capacities.

Additionally, another study by Javid et al. (2) showed that the costs calculated through $\mathrm{ABC}$ considerably differed from that of the traditional method. Beyond that, the $\mathrm{ABC}$ method yields more accurate information concerning the main components of costs (2). Also, Kazemi et al. (30) showed that governmental tariffs cannot cover the costs of wards and they have to be subsidized by the government in order to compensate for loss.

Similarly, the findings of the study done at the laboratory of Tehran (11) showed that the total cost of services was $63 \%$ higher than the governmental tariffs in the country.

Simply put, these results are consistent with the findings of the current study. This price gap in the present study can be the result of weakness of tariffing system in Iran, which does not follow any exact and scientific method. Another reason can be attributed to investment costs (depreciation of building, medical and non-medical equipment), which is one of the most important costs in determining the cost of services that state owned hospital provide services as a non-profit organization and most of the equipment present there are supplied by the government. The depreciation costs of building, property, as well as the cost of medical and non-medical equipment 
are not calculated which might lead to a considerable difference in the total cost of the services. Another reason, which can be considered as a factor contributing to this cost difference includes implementation of healthcare reform plan, which increases costs such as human resources cost. Moreover, imposing sanctions on the government (by other countries) coupled with bad economic conditions during the recent years could have increased manpower cost and the cost of consumable materials.

\subsection{Conclusions}

The discrepancy between the approved tariffs and the total cost of surgeries was considerable, which is indicative of the notion that the approved tariffs cannot completely cover the cost of these surgeries. This difference can seriously affect any given hospital's performance, which has a vital role in providing services to the community; therefore, negatively affecting the quality of the services provided. It seems that what has escaped the attention of those responsible for tariffing services is that they must consider depreciation cost together with the costs, which are redundantly imposed on the output-oriented activity centers. These are exactly the issues that can be identified with the ABC system as opposed to traditional methods.

Considering that the costs of human resources, indirect, and depreciation of equipment make up more than $90 \%$ of the costs, the hospital management must attend to both the improvement of the effectiveness of the cost and to decreasing the costs.

\subsection{Limitation}

Some of the study's limitations were diversity of services, poor cooperation of personnel in delivering information about their activities in the departments as well as in collecting and agreeing on cost drivers.

\section{Acknowledgments}

We sincerely thank all the people, who were involved in the studied hospitals for their help and cooperation during the data collection process.

\section{Footnotes}

Authors' Contribution: Ali Janati: study supervision, preparation, review and approval of the manuscript; Mohammad Farough Khosravi: design and conduct of the study, collection and analysis of the data, and preparation, review and approval of the manuscript; Ali Imani: study supervision, analysis of the data, preparation, review and approval of the manuscript; Alireza Javadzadeh: data collection; Mohammad Ali Mazhar Gharamaleki: data collection.
Funding/Support: This study was part of a MSc. thesis supported by Tabriz University of Medical Sciences (Thesis NO: 236/A/M, ethical code: TBZMED.REC.1394.215).

\section{References}

1. Abdul Majid J, Sulaiman M. Implementation of activity based costing in Malaysia: A case study of two companies. Asian Review of Accounting. 2008;16(1):39-55. doi: 10.1108/13217340810872463.

2. Javid M, Hadian M, Ghaderi H, Ghaffari S, Salehi M. Application of the Activity-Based Costing Method for Unit-Cost Calculation in a Hospital. GlobJ Health Sci. 2016;8(1):165-72. doi: 10.5539/gjhs.v8n1p165. [PubMed: 26234974].

3. Jabbari A, Keyvan Ara M, Rahi FA, Ziz Zadeh M. Perception of insurance organization managers on the concept of real tariff of medical services in the health system: A qualitative study. J Qualitative Res Health Sci. 2015;4(3):304-13.

4. Doshmangir L, Rashidian A, Akbari SA. Unresolved issues in medical tariffs: Challenges and respective solutions to improve tariff system in Iranian health sectors. J Hospital Infect. 2012;10(4):21-30.

5. Doshmangir L, Rashidian A, Moaeiri F, Akbari SA. Effect of proposed changes of relative values of different specialists medical tariffs on payment weight of specialties and health system costs. Hakim. 2011;14(1):1-9.

6. Zare H, Akhavan Behbahani A, Azadi M, Masoudi Asl I. Assessment of Methods for Determination of Medical Tariffs in Developed Countries and Proposing a Model for Iran. Majlis and Rahbord. 2013;20(74):5-34.

7. Jafari M, Rashidian A, Abolhasani F, Mohammad K, Yazdani S, Parkerton P, et al. Space or no space for managing public hospitals; a qualitative study of hospital autonomy in Iran. Int J Health Plann Manage. 2011;26(3):121-37. doi: 10.1002/hpm.1050. [PubMed: 20669188].

8. Noori MMK. Manavi Study of policy making and rating the challenges ofmedical tariff (Research project). Tehran, Iran: Islamic Parliament Research Center; 2008.

9. Zare HBM, Rasel M, Keshavarz KH. Tariff practices in the health sector (Theoretical and global perspective, comparative studies, templates). Tehran, Iran: Hospital Management Research Center: Tehran University of Medical Sciences; 2011.

10. Kalhor R, Amini S, Emami M, Kakasoltani K, Rhamani N, Kalhor L. Comparison of the Ministry of Health's tariffs with the cost of radiology services using the activity-based costing method. Electron Physician. 2016;8(2):2018-24. doi: 10.19082/2018. [PubMed: 27054013].

11. Nouroozi T, Salehi A. Prime costs of clinical laboratory services in Tehran Valiasr Hospital in 2009/Cout primaire des services de laboratoires cliniques a 1 hopital Valiasr de Teheran en 2009. Eastern Mediterranean Health J. 2013;19(3):159.

12. Rajabi A, Dabiri A. Applying Activity Based Costing (ABC) Method to Calculate Cost Price in Hospital and Remedy Services. Iran J Public Health. 2012;41(4):100-7. [PubMed: 23113171].

13. Moreno K. Adaptation of activity-based-costing (ABC) to calculate unit costs in Mental Health Care in Spain. European J Psychiatr. 2007;21:11723. doi: 10.4321/S0213-61632007000200003.

14. Rajabi A. . The role of activity based costing (ABC) system in governmental hospital services in Iran. Iran Red Crescent Med J. 2008;10(2):89-94.

15. van Rensburg AJ, Jassat W. Acute mental health care according to recent mental health legislation Part II. Activity-based costing. Afr J Psychiatr. 2011;14(1) doi: 10.4314/ajpsy.v14i1.65464.

16. Ergun FA, Agirbas I, Kuzu I. Activity-based costing for pathology examinations and comparison with the current pricing system in Turkey.TurkPatoloji Derg. 2013;29(1):1-14. doi:10.5146/tjpath.2013.01141. [PubMed: 23354790]. 
17. Atif M, Sulaiman SA, Shafie AA, Saleem F, Ahmad N. Determination of chest $\mathrm{x}$-ray cost using activity based costing approach at Penang General Hospital, Malaysia. Pan Afr Med J. 2012;12:40. [PubMed: 22891098].

18. Goldberg MJ, Kosinski L. Activity-based costing and management in a hospital-based GI unit. Clin Gastroenterol Hepatol. 2011;9(11):947-949 e1. doi: 10.1016/j.cgh.2011.08.010. [PubMed: 22018055].

19. Rasiah $\mathrm{D}$. Why Activity Based Costing $(\mathrm{ABC})$ is still tagging behind the traditional costing in Malaysia? J Applied Finance Banking. 2011;1(1):83.

20. Duffy JH, Totten MK, Orlikoff JE. Trends and strategic planning: implications for the board. Trustee. 2008;61(10):suppl 17-20. [PubMed: 19093426].

21. Tibesku CO, Hofer P, Portegies W, Ruys CJ, Fennema P. Benefits of using customized instrumentation in total knee arthroplasty: results from an activity-based costing model. Arch Orthop Trauma Surg. 2013;133(3):405-11. doi: 10.1007/s00402-012-1667-4. [PubMed: 23242451].

22. Farahani Jam F. The new findings, researchers Iran's about physical and mechanical parameters of the eye tissue Jame Jam Iran; 2008 2016. Available from: http://www1.jamejamonline.ir/papertext. aspx? newsnum=100951764622.

23. Beyranvand R, Ebadi Fard Azar F, Emamgholipour S, Arab M. UnitCost Calculation of Delivered Services Based on Activity Based Costing (ABC) Method Compared with Approved Tariffs in Physiotherapy Department of Sina Hospital Affiliated to Tehran University of Medical
Sciences in 2013-2014. J Hospital. 2016;15(2):49-58.

24. Rajabi A. . Applying ABC System for Calculating Cost Price of Hospital Services Case Study: Shahid Faghihi Hospital of Shiraz. National Project Ministry of Health and Medical Education; 2005.

25. Doyle G, Duffy L, McCahey M. An empirical study of adoption/nonadoption of activity based costing in hospitals in Ireland. Canada: Administration Sciences Association of Canada, Dalhousie University; 2008.

26. Eden R, Lay C, Maingot M. Preliminary findings on abc adoption in canadian hospitals: Reasons for low rates of adoption. Irish Accounting Review. 2006;13(2).

27. Nouroozi T, Reza Vadiee G, Ravangard R. Prime costs of hospital services in Ghaem hospital in Firouzabad, Fars. European Online J Natural and Social Sci. 2014;2(3):3067-74.

28. JHospital Infect. Unresolved issues in medical tariffs: Challenges and respective. Hospital. 2012;10(4):21-30.

29. Antikainen K, Roivainen T, Hyvarinen M, Toivonen J, Karri T. Activitybased costing process of a day-surgery unit-from cost accounting to comprehensive management. Frontiers of e-business research Conference proceedings of eBFR Febr. 2005.

30. Kazemi Z, Zadeh HA. Activity based Costing: A Practical Model for Cost Price Calculation in Hospitals. Indian J Sci Technol. 2015;8(27) doi: 10.17485/ijst/2015/v8i27/81871. 